Article

\title{
Synthesis and Characterization of Ethylenedithio-MPTTF-PTM Radical Dyad as a Potential Neutral Radical Conductor
}

\author{
Manuel Souto ${ }^{1}$, Dan Bendixen ${ }^{2}$, Morten Jensen ${ }^{2}$, Valentín Díez-Cabanes ${ }^{3}$, Jérôme Cornil ${ }^{3}$, \\ Jan O. Jeppesen ${ }^{2}$, Imma Ratera ${ }^{1, *}$, Concepció Rovira ${ }^{1}$ and Jaume Veciana ${ }^{1, *}$ \\ 1 Department of Molecular Nanoscience and Organic Materials, Institut de Ciència de Materials de \\ Barcelona (ICMAB-CSIC)/CIBER-BBN, Campus de la UAB, 08193 Bellaterra, Spain; \\ msouto@icmab.com (M.S.); cun@icmab.es (C.R.) \\ 2 Department of Physics, Chemistry and Pharmacy, University of Southern Denmark, 5230 Odense, Denmark; \\ danbendixen88@hotmail.com (D.B.); mortenj@sdu.dk (M.J.); joj@sdu.dk (J.O.J.) \\ 3 Laboratory for the Chemistry of Novel Materials, Université de Mons, 7000 Mons, Belgium; \\ valentin.diez@hotmail.com (V.D.-C.); jerome.cornil@umons.uc.be (J.C.) \\ * Correspondence: iratera@icmab.es (I.R.); vecianaj@icmab.es (J.V.); Tel.: +34-935-801-853 (I.R. \& J.V.)
}

Academic Editor: Manuel Almeida

Received: 3 November 2016; Accepted: 9 December 2016; Published: 16 December 2016

\begin{abstract}
During the last years there has been a high interest in the development of new purely-organic single-component conductors. Very recently, we have reported a new neutral radical conductor based on the perchlorotriphenylmethyl (PTM) radical moiety linked to a monopyrrolotetrathiafulvalene (MPTTF) unit by a $\pi$-conjugated bridge (1) that behaves as a semiconductor under high pressure. With the aim of developing a new material with improved conducting properties, we have designed and synthesized the radical dyad $\mathbf{2}$ which was functionalized with an ethylenedithio (EDT) group in order to improve the intermolecular interactions of the tetrathiafulvalene (TTF) subunits. The physical properties of the new radical dyad 2 were studied in detail in solution to further analyze its electronic structure.
\end{abstract}

Keywords: neutral organic radical; perchlorotriphenylmethyl radical; tetrathiafulvalene; donor-acceptor

\section{Introduction}

During the past few years there has been a growing interest in the development of purely-organic single-component conductors [1,2]. The interest of such systems is that they offer the possibility of three-dimensional electronic structure, because of the absence of any counterion [3]. However, realization of purely-organic single-component conductors is a major challenge since organic materials are normally insulating.

One interesting possibility to achieve this goal is to use neutral organic radicals as single-component conductors. Although most neutral radicals behave as a Mott insulator, high conductivity can be attained if the electronic bandwidth $W$, which is directly related to the intermolecular interactions, is maximized and the intra-site Coulomb repulsion energy $U$ is minimized. In this sense, most of these systems are based on delocalized and planar radicals in order to increase the $W / U$ ratio, such as spirobisphenalenyl [4-6] and thiazolyl radicals [7-9] reported by Haddon and Oakley, respectively. In addition, Mori and coworkers have also recently reported a purely-organic single-component conductor by utilizing strong hydrogen-bonding interactions between tetrathiafulvalene (TTF)-based electron-donor molecules [10,11].

In this direction, we have very recently reported the organic donor-acceptor (D-A) dyad 1 based on the non-planar and spin localized radical perchlorotriphenylmethyl (PTM) radical linked to 
a monopyrrolo-tetrathiafulvalene (MPTTF) unit that exhibited semiconducting behavior with high conductivity upon application of high pressure [12-15]. The origin of such conducting behavior was attributed to the increased electronic bandwidth $W$, thanks to short intermolecular interactions between the MPTTF and PTM subunits, and the decreasing of the Coulomb repulsion energy $U$ due to the charge reorganization occurring at high pressure. The intramolecular charge transfer between the TTF and PTM moieties, as demonstrated by the formation of charge-separated zwitterionic species in solution when using polar solvents [12,13], is an optimal condition for obtaining neutral radical conductors since the Coulomb repulsion energy $U$ can be minimized.

To design and obtain new neutral radicals based on this family of compounds exhibiting higher conductivity, one synthetic approach could be the functionalization of the MPTTF unit with an ethylenedithio (EDT) group in order to increase the intermolecular interactions as it has been reported for several organic superconductors [16]. Thus, in this article we report the synthesis and characterization of the D-A radical dyad 2 (EDT-MPTTF-PTM) which contains the same molecular structure as $\mathbf{1}$ but is functionalized with an EDT group in order to improve the self-assembly between the radical molecules (Scheme 1). Subsequently, we evaluate the physical properties in solution of the radical dyad 2 that could be a neutral radical conductor in the solid state.
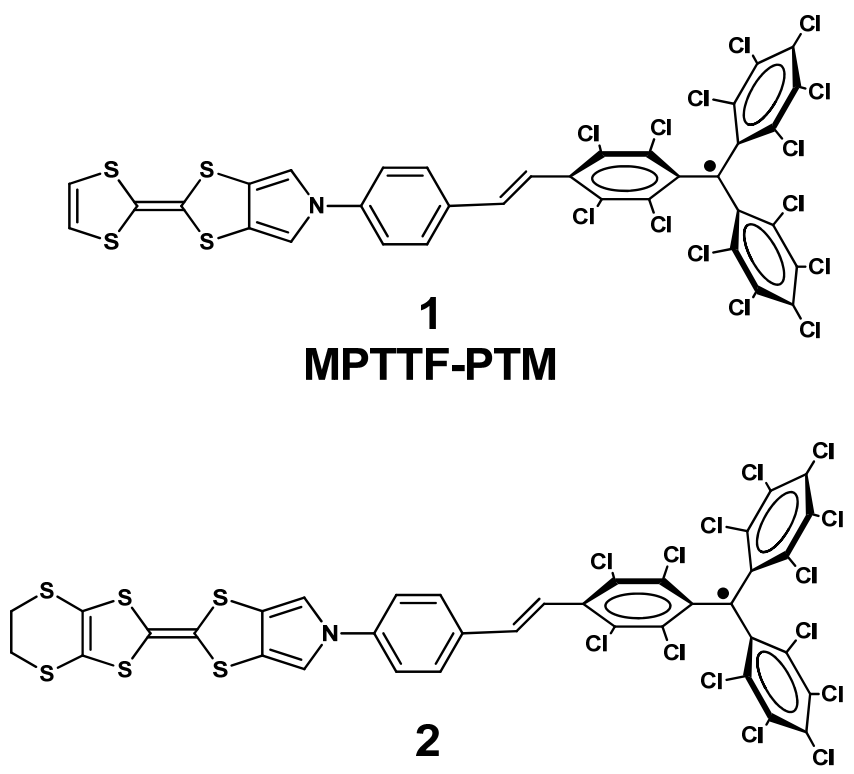

EDT-MPTTF-PTM

Scheme 1. Molecular structures of the monopyrrolo-tetrathiafulvalene (MPTTF)-perchlorotriphenylmethyl (PTM) (1); and ethylenedithio (EDT)-MPTTF-PTM (2) radical dyads.

\section{Results and Discussion}

\subsection{Synthesis}

The strategy to synthesize dyad 2 was based on the Wittig-Horner coupling between the phosphonated PTM derivative 8 [17] and the EDT-MPTTF aldehyde 7 functionalized with an ethylenedithio group.

The synthesis of the aldehyde precursor 7 was carried out as outline in Scheme 2. First, the cross-coupling of the ethylendithio-thione (3) [18] and 5-tosyl-(1,3)-dithiolo[4,5-c]pyrrole-2-one (4) [19] in anhydrous $(\mathrm{EtO})_{3} \mathrm{P}$ gave 5 in $82 \%$ yield after column chromatography. Subsequently, the tosyl protecting group on derivative 5 was removed using $\mathrm{NaOMe}$ in a THF/MeOH mixture to obtain compound 6 as a yellow solid which was used in the next reaction without further purification. Finally, by mixing derivative 6, 4-bromobenzaldehyde, an excess of cuprous iodide (CuI), and trans-1,2-diaminocyclohexane gave compound 7 in $41 \%$ overall yield (from compound 5). 
<smiles>S=c1sc2c(s1)SCCS2</smiles>

3<smiles>O=c1sc2cn([134I])cc2s1</smiles>

4

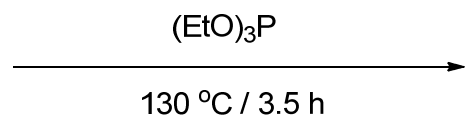

$82 \%$

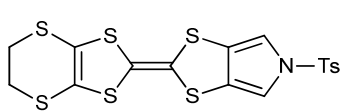

5

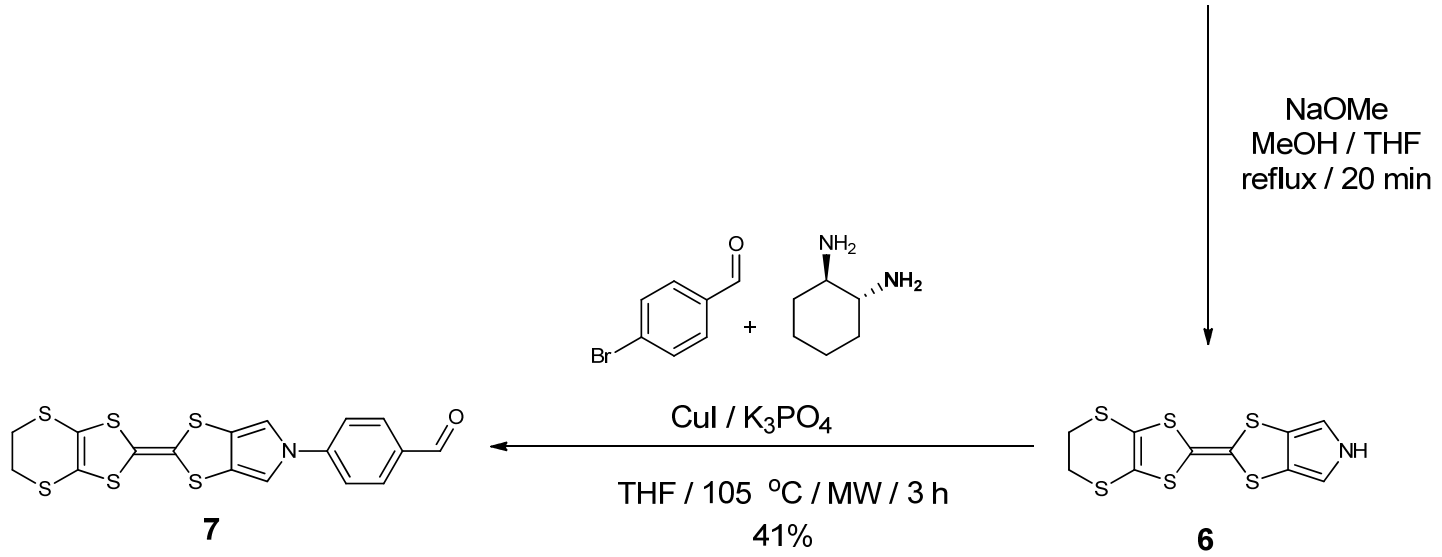

Scheme 2. Synthesis of compound 7. Ts = tosyl.

Radical dyad 2 was synthesized in three steps, as summarized in Scheme 3. First, compound 9 was obtained in a 52\% yield through a Horner-Wadsworth-Emmons reaction of aldehyde 7 and the phosphonated PTM derivative 8 and was fully characterized (Figures S1-S3) [17]. Subsequent deprotonation and oxidation of the generated carbanion with silver nitrate provided radical dyad 2 $(69 \%)$ as a black solid.
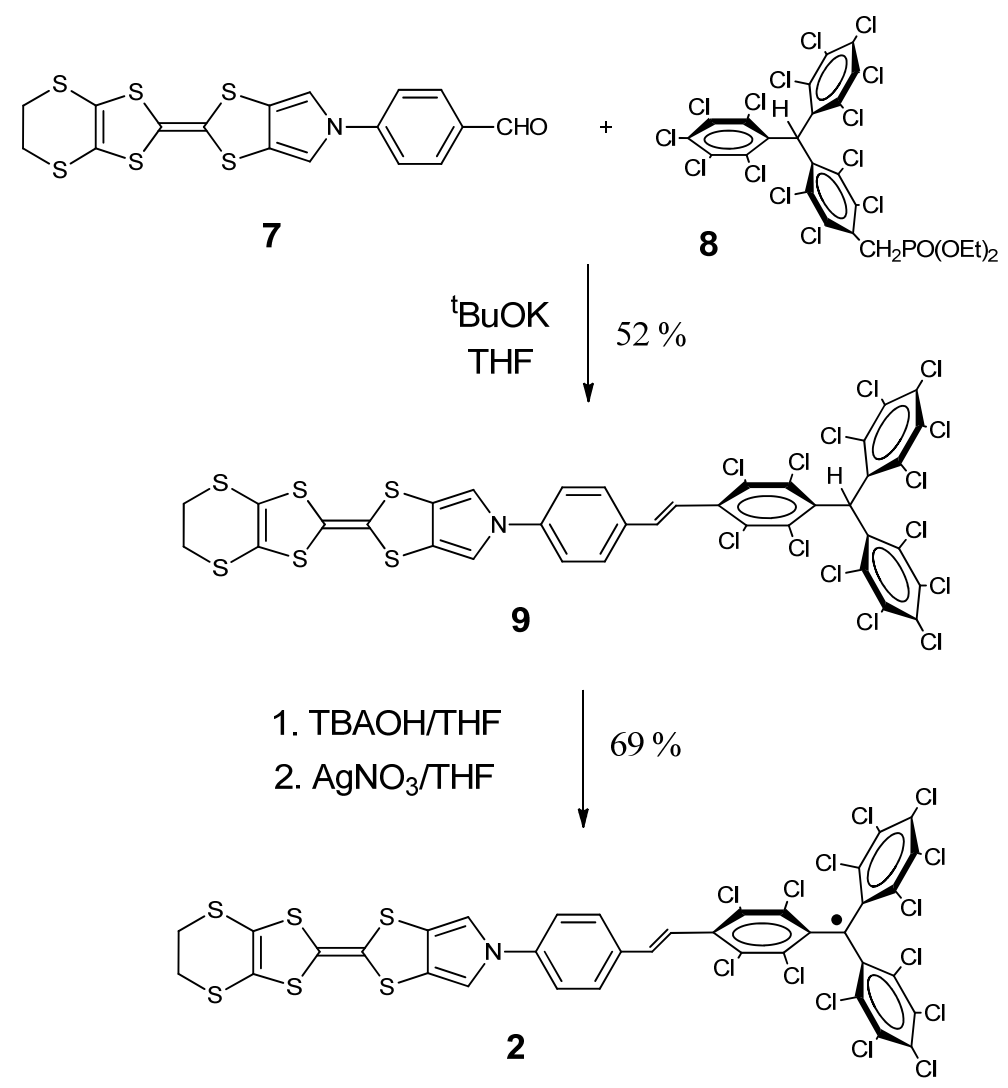

Scheme 3. Synthesis of radical dyad 2. 


\subsection{Characterization}

\subsubsection{Electrochemical Properties}

Figure 1 displays the cyclic voltammograms $(\mathrm{CV})$ of radical dyads $\mathbf{1}$ and $\mathbf{2}$ recorded in $\mathrm{CH}_{2} \mathrm{Cl}_{2}$ at room temperature. Both dyads exhibit three reversible waves assigned to the following redox pairs: $\mathrm{PTM}^{-} / \mathrm{PTM}^{-}\left(E^{\text {red }}{ }_{1 / 2}\right), \mathrm{MPTTF}_{\mathrm{MPTTF}}{ }^{+\cdot}\left(E^{\mathrm{ox} 1}{ }_{1 / 2}\right)$, and $\mathrm{MPTTF}^{+\cdot} / \mathrm{MPTTF}^{2+}\left(E^{\mathrm{ox} 2} 1 / 2\right)$. The difference between the reduction and the first oxidation potential, $\left(\Delta E^{(1)}\right)$, is directly related to the intrasite Coulomb repulsion energy $U$ of the neutral radical compound and should be minimized for obtaining optimal molecular conductors [13]. As it transpires from Table 1, $\Delta E^{(1)}$ was smaller for radical dyad 1 indicating that the repulsion energy $U$ was slightly increased in radical dyad 2 . On the other hand, the difference between the first and second oxidation potential, $\left(\Delta E^{(2)}\right)$, slightly decreases in the case of radical dyad 2.

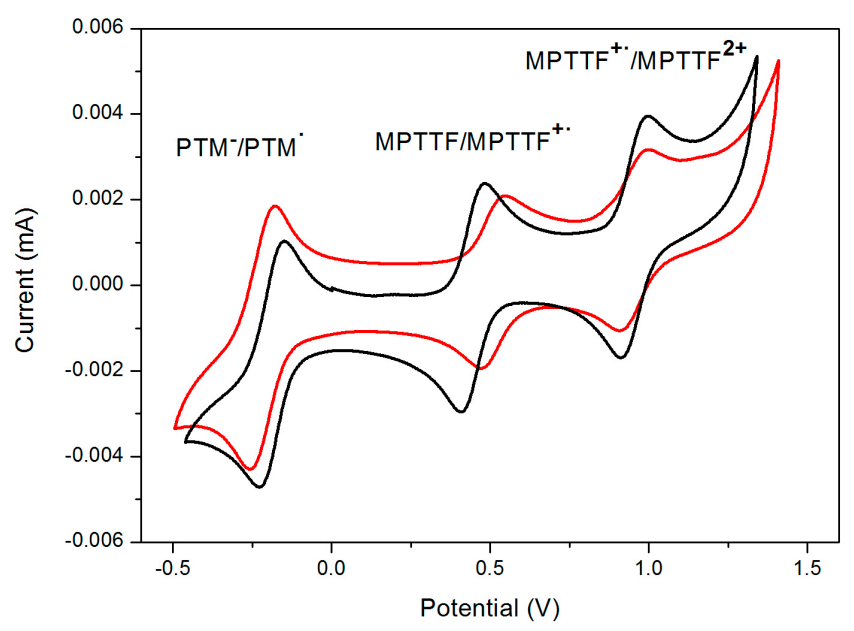

Figure 1. Cyclic voltammograms of dyads $\mathbf{1}$ (black line) and 2 (red line) in $\mathrm{CH}_{2} \mathrm{Cl}_{2}$ versus $\mathrm{Ag} / \mathrm{AgCl}$ with $\mathrm{Bu}_{4} \mathrm{NPF}_{6}(0.1 \mathrm{M})$ as electrolyte at $300 \mathrm{~K}$ under argon at scan rate of $0.1 \mathrm{~V} / \mathrm{s}$.

Table 1. Electrochemical data of radical dyads $\mathbf{1}$ and 2.

\begin{tabular}{|c|c|c|c|c|c|}
\hline Dyad & $E^{\mathrm{red}}{ }_{1 / 2}(\mathrm{~V})$ & $E_{1 / 2}^{o x 1_{1 / 2}}$ & $E_{1 / 2}^{o \times 2}(\mathrm{~V})$ & $\Delta E^{(1)}(\mathrm{V})^{\mathrm{a}}$ & $\Delta E^{(2)}(\mathrm{V})^{\mathrm{b}}$ \\
\hline 1 & -0.19 & +0.45 & +0.95 & +0.64 & +0.50 \\
\hline 2 & -0.22 & +0.51 & +0.95 & +0.73 & +0.44 \\
\hline
\end{tabular}

\subsubsection{Optical Properties}

The UV-vis-near infrared (NIR) spectra of dyads 1 and 2 were recorded in $\mathrm{CH}_{2} \mathrm{Cl}_{2}$ at $300 \mathrm{~K}$ (Figure 2) and show similar bands. The intense peak at $385 \mathrm{~nm}$ corresponds to the radical chromophore of the PTM subunit and the shoulders appearing around 450 and $550 \mathrm{~nm}$ are assigned to the electronic conjugation of the unpaired electron into the conjugated $\pi$-framework [12]. The lowest energy band, which appears around $800 \mathrm{~nm}$, is ascribed to the intramolecular charge transfer (ICT) occurring between the electron-donor TTF and electron-acceptor PTM units. This band appears at similar energies for both dyads indicating that compounds $\mathbf{1}$ and $\mathbf{2}$ exhibit a similar degree of charge transfer.

On the other hand, we have observed a bistable behavior in solution, between neutral and zwitterionic species, for similar TTF-PTM dyads that can be switched by tuning the polarity of the solvents $[12,20,21]$. In order to evaluate this bistability phenomenon in solution for this new system, we recorded the optical spectra of radical dyad 2 in three solvents with different polarities $\left(\mathrm{CH}_{2} \mathrm{Cl}_{2}, \mathrm{Me}_{2} \mathrm{CO}\right.$ and DMF) (Figure 3). As we can observe, dyad 2 was present in the neutral state in $\mathrm{CH}_{2} \mathrm{Cl}_{2}$ and $\mathrm{Me}_{2} \mathrm{CO}$ since we only observed the band at $387 \mathrm{~nm}$ attributed to the radical neutral 
species. Thus, the bistability of dyad 2 was only observed in the most polar solvent (i.e., DMF), as demonstrated by the presence of the intense band at $512 \mathrm{~nm}$ attributed to the anionic form of the PTM unit due to the formation of zwitterionic species. Moreover, solution of dyad 2 in DMF was ESR silent suggesting that the zwitterionic species formed diamagnetic dimers as it has been observed for similar TTF-PTM dyads $[12,14,20]$. Most of the absorption bands related to the TTF radical cation dimer are overlapped by the intense absorption band related to the PTM anion as it has been previously observed (Figure S4) [22]. This behavior was similar for dyad $\mathbf{1}$ [12] indicating that dyads $\mathbf{1}$ and $\mathbf{2}$ exhibit similar electronic properties. DFT calculations confirmed that frontier molecular orbitals were similar for dyads 1 and $\mathbf{2}$ (Supplementary Materials Figure S4). This bistable behavior in solution suggests that a charge transfer between the TTF and PTM units in dyad $\mathbf{2}$ can be promoted upon application of an external stimulus (i.e., solvent polarity, high pressure, temperature, etc.). This charge reorganization is an optimal condition for obtaining neutral radical conductors since the Coulomb repulsion energy $U$ can be minimized [13].

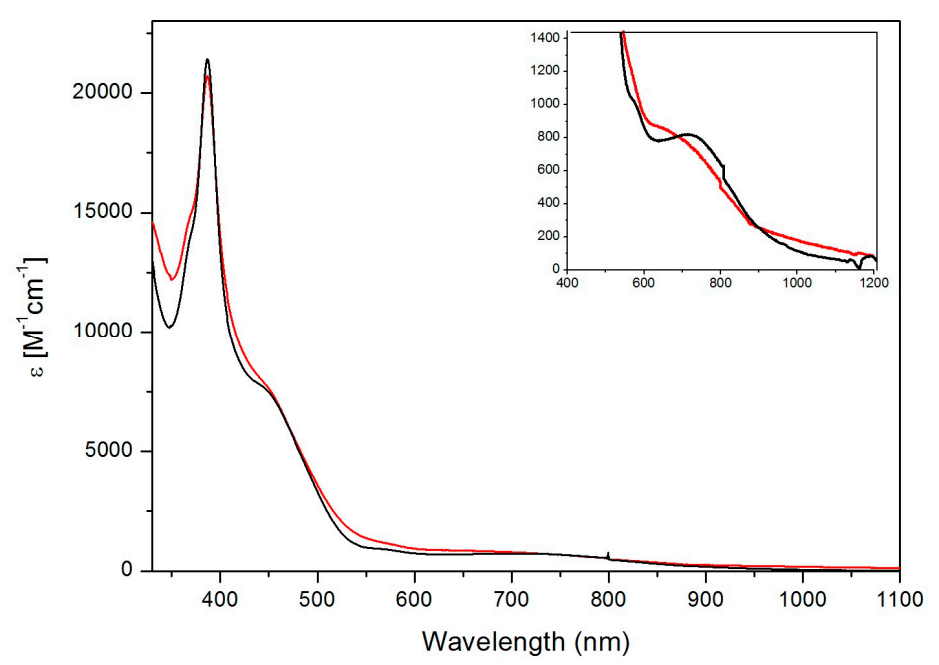

Figure 2. UV-vis-near infrared (NIR) spectra recorded in $\mathrm{CH}_{2} \mathrm{Cl}_{2}$ at $300 \mathrm{~K}$ of a $0.05 \mathrm{mM}$ solution of dyads 1 (black line) and 2 (red line). The inset shows the low-energy range of the absorption spectra of 1 and 2.

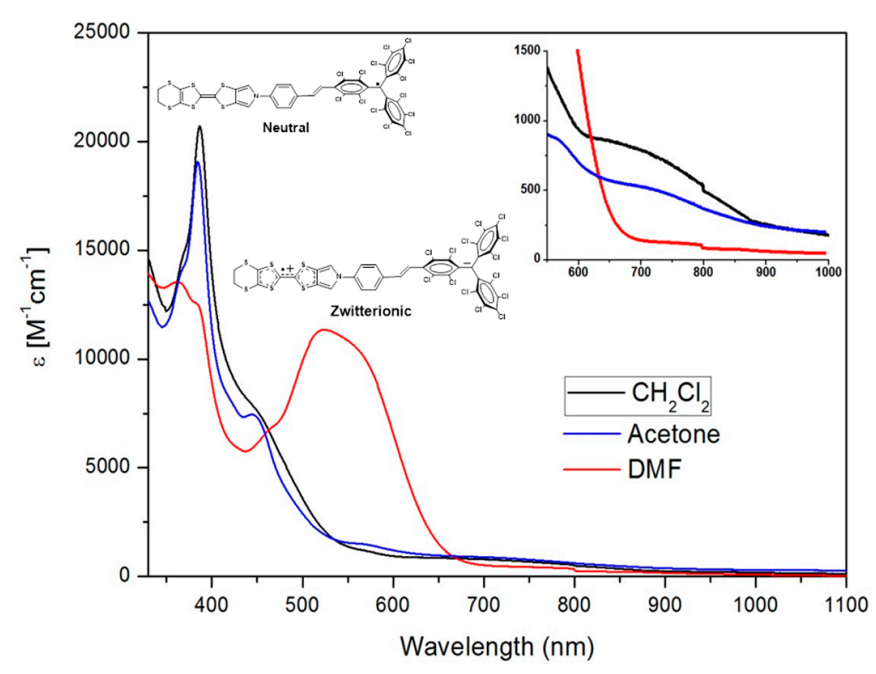

Figure 3. UV-vis-NIR spectra of radical dyad 2 recorded in $\mathrm{CH}_{2} \mathrm{Cl}_{2}$ (black line), $\mathrm{Me}_{2} \mathrm{CO}$ (blue line) and DMF (red line) at $300 \mathrm{~K}$. Molecular structures of the possible neutral and zwitterionic states for radical dyad 2. The inset shows the low-energy range of the absorption spectra. 


\subsubsection{Magnetic Properties}

Magnetic properties were studied in solution by Electron Spin Resonance (ESR) spectroscopy. The ESR spectrum of radical dyad 2 recorded in $\mathrm{CH}_{2} \mathrm{Cl}_{2}(0.05 \mathrm{mM})$ at room temperature (Figure 4) showed two main lines with a $g$-value of 2.0025 corresponding to the hyperfine coupling of the unpaired electron with one ${ }^{1} \mathrm{H}$ atom of the vinylene bridge. The isotropic hyperfine coupling constants with such a proton showed the typical values for vinyelene-substituted PTM radicals $\left(a_{\mathrm{H}}=1.9 \mathrm{~Hz}\right.$; $\Delta H_{\mathrm{pp}}=1.1 \mathrm{~Hz}$ ). The few satellite weak lines are attributed to the hyperfine coupling of the unpaired electron with naturally abundant ${ }^{13} \mathrm{C}$ isotopes at the $\alpha$ and aromatic positions.

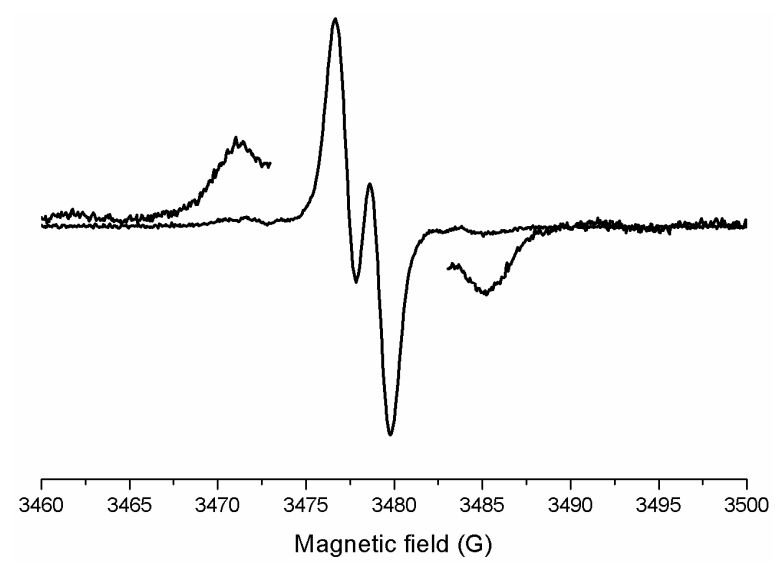

Figure 4. Electron Spin Resonance (ESR) spectrum recorded of a $0.05 \mathrm{mM}$ solution of radical dyad 2 in $\mathrm{CH}_{2} \mathrm{Cl}_{2}$ at $300 \mathrm{~K}$.

On the other hand, we generated $\mathbf{2}^{\bullet+}$ by chemical oxidation with $\mathrm{FeCl}_{3}$ (Figure S5) and recorded ESR spectra at different temperatures (220-300 K) (Figure 5). The ESR spectrum at room temperature consists of two separated groups of lines (a single line and two symmetrical lines) with $g$ values of 2.0056 and 2.0029 attributed to the open-shell $\mathrm{TTF}^{\bullet+}$ and $\mathrm{PTM}^{\bullet}$ radical subunits, respectively. When temperature is lowered, the lines associated with both TTF and PTM units progressively decreased in intensity and the intensity of the TTF line disappeared completely at $220 \mathrm{~K}$. These changes were completely reversible with temperature and this behavior was consistent with the dimerization of $\mathbf{2}^{\bullet+}$ at low temperature as it has already been observed for other TTF-PTM oxidized dyads [22].

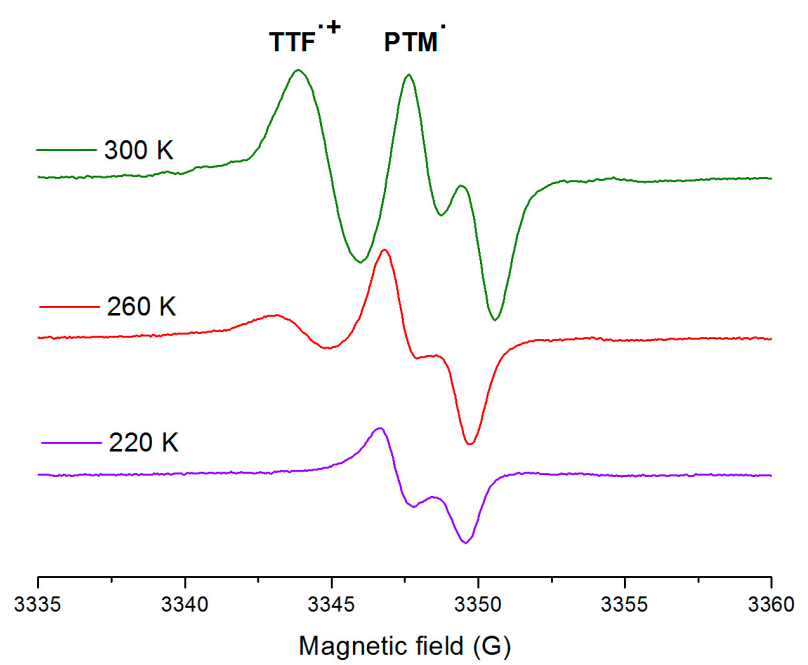

Figure 5. ESR spectra of $2^{\cdot+}$ recorded in THF $(0.05 \mathrm{mM})$ at 300 (green line), 260 (red line) and $220 \mathrm{~K}$ (purple line). 
As noted previously for similar systems [22], the observation that the intensity of the ESR signal decreases when decreasing the temperature suggests that in the dimer $\left[2^{\bullet+}\right]_{2}$ the two $\mathrm{TTF}^{\bullet+}$ subunits are magnetically coupled in a singlet (ESR-silent) ground state and, in addition, are able to transmit an antiferromagnetic coupling between the two unpaired spins of the PTM subunits. Such behavior indicates that there is a great intermolecular interaction between the dyads $\mathbf{2}$ which is an important prerequisite for obtaining optimal molecular conductors in the solid state.

Concerning the properties in solid state of radical dyad 2, the external and additional sulfur atoms as well as the ethylene groups could play a key role in obtaining an optimal crystal packing since it is well known that S..S and C-H..S interactions are very useful as secondary-interactions to achieve supramolecular assemblies of TTF derivatives [16]. Therefore, we expect that intermolecular interactions in dyad $\mathbf{2}$ will be increased in comparison to dyad $\mathbf{1}$ and that the electronic bandwidth $\mathrm{W}$ will be enhanced. On the other hand, although the estimated Coulomb repulsion energy $U$ of 2 seems to increase in comparison with 1 from the $\mathrm{CV}$, we expect that charge transfer occurring between the TTF and PTM subunits, as it has been observed in solution, will help to decrease such repulsion energy.

In view of the promising conducting properties that could exhibit crystals of dyad 2, several efforts for crystallizing the neutral compound has been realized by diffusion and slow evaporation methods using different solvents (hexane, toluene, $\mathrm{CH}_{2} \mathrm{Cl}_{2}, \mathrm{Et}_{2} \mathrm{O} \ldots$ ) and conditions (temperature, concentration ... ). Unfortunately, up to now, it has not been possible to obtain crystals of high quality which has prevented the determination of its X-ray crystal structure. Moreover, in view of the several reported examples of magnetic conductors and superconductors based on BEDT-TTF charge transfer salts [16], it is also planned to obtain radical ion-salts based on dyad 2 by electrocrystallization in the future. Thus, we will continue our efforts for crystallizing such compounds that could have a potential use in spintronics if they are able to combine both conductivity and magnetism in a cooperative manner, as the spin-polarized donor radicals reported by Sugawara and coworkers [23].

\section{Materials and Methods}

\subsection{General Methods for Synthesis and Characterization}

All reagents and solvents employed for the syntheses were of high purity grade and were purchased from Sigma-Aldrich Co. (St Louis, MO, USA), Merck (Darmstadt, Germany), and SDS, except compound 3 [18] and 4 [19] which were synthesized according to literature procedures Anhydrous solvents were used in the chemical reactions and for recording the cyclic voltammograms. ${ }^{1} \mathrm{H}$ NMR spectra were recorded using a Bruker Avance 250, 400, or 500 instruments (Bruker, Billerica, MA, USA) and $\mathrm{Me}_{4} \mathrm{Si}$ was used an internal standard. Infrared spectra were recorded with Spectrum One FT-IR Spectroscopy instrument (Perkin Elmer, Waltham, MA, USA) and UV/Vis/NIR spectra were measured using Cary 5000E Varian (Agilent, Santa Clara, CA, USA). ESR spectra were performed with a Bruker ESP 300 E (Bruker, Billerica, MA, USA) equipped with a rectangular cavity T102 that works with an X-band $(9.5 \mathrm{GHz})$. The solutions were degassed by argon bubbling before the measurements. LDI/TOF MS were recorded in a Bruker Ultraflex LDI-TOF spectrometer (Bruker, Billerica, MA, USA). Cyclic voltammetry measurements were obtained with a potentiostat 263a (Ametek, Berwyn, PA, USA) from EG\&G Princeton Applied Research in a standard 3 electrodes cell. The IR-NIR spectra have been collected with a Bruker FT-IR IFS-66 spectrometer (Perkin Elmer, Waltham, MA, USA) equipped with a Hyperion microscope. The spectral resolution is about $2 \mathrm{~cm}^{-1}$ for both spectrometers. The manipulation of the radicals in solution was performed under red light.

\subsection{Synthesis and Characterization}

Compound 1 was synthesized as reported in reference [12].

Compound 5: Anhydrous $(\mathrm{EtO})_{3} \mathrm{P}(40 \mathrm{~mL})$ was heated to $130{ }^{\circ} \mathrm{C}$ before the thione $3(1.10 \mathrm{~g}$, $4.90 \mathrm{mmol})$ and the ketone $4(0.99 \mathrm{~g}, 3.18 \mathrm{mmol})$ were added. After stirring the reaction mixture at $130{ }^{\circ} \mathrm{C}$ for $10 \mathrm{~min}$, an additional portion of $3(1.08 \mathrm{~g}, 4.81 \mathrm{mmol})$ was added, then the reaction mixture 
was heated at $130{ }^{\circ} \mathrm{C}$ for $3.5 \mathrm{~h}$. The reaction mixture was cooled to room temperature, whereupon cold $\mathrm{MeOH}\left(50 \mathrm{~mL},-18{ }^{\circ} \mathrm{C}\right)$ was added. Leaving the mixture overnight at $-18{ }^{\circ} \mathrm{C}$ produced a yellow precipitate, which was filtered off and washed with cold $\mathrm{MeOH}\left(3 \times 20 \mathrm{~mL},-18^{\circ} \mathrm{C}\right)$. The yellow solid was dissolved in $\mathrm{CH}_{2} \mathrm{Cl}_{2}(500 \mathrm{~mL})$ and Celite $545(40 \mathrm{~mL})$ was added, before the solvent was removed in vacuo. The resulting residue was purified by column chromatography (silica gel: $1 . \mathrm{CH}_{2} \mathrm{Cl}_{2} /$ petroleum ether (b.p. $60-80{ }^{\circ} \mathrm{C}$ ) $1: 1,2 . \mathrm{CH}_{2} \mathrm{Cl}_{2}$ ) and the broad yellow band was collected and concentrated to the give the title compound 5 as a yellow powder containing traces of grease. Yield $(1.27 \mathrm{~g}, 82 \%)$. Characterization: M.p. $>250{ }^{\circ} \mathrm{C} .{ }^{1} \mathrm{H}-\mathrm{NMR}\left(\mathrm{CDCl}_{3}\right): \delta=2.41(\mathrm{~s}, 3 \mathrm{H}), 3.29(\mathrm{~s}, 4 \mathrm{H}), 6.93(\mathrm{~s}, 2 \mathrm{H}), 7.30$ $(\mathrm{d}, 2 \mathrm{H}, J=8.3 \mathrm{~Hz}), 7.72(\mathrm{~d}, 2 \mathrm{H}, J=8.3 \mathrm{~Hz})$. MS (ESI): $m / z=486\left(\mathrm{M}^{+}\right)$. HiRes-FT ESI-MS: Calculated $m / z=486.8991$; Found $m / z=486.8987$. IR $(\mathrm{KBr}): v / \mathrm{cm}^{-1}=3125 ; 2919 ; 1595 ; 1371 ; 1225 ; 1188 ; 1171$; $1090 ; 1054$.

Compound 7: A solution of the MPTTF compound $5(0.390 \mathrm{~g}, 0.800 \mathrm{mmol})$ in a mixture of anhydrous THF $(50 \mathrm{~mL})$ and anhydrous $\mathrm{MeOH}(50 \mathrm{~mL})$ was degassed $\left(\mathrm{N}_{2}, 20 \mathrm{~min}\right.$.), before a solution of $\mathrm{NaOMe}$ in $\mathrm{MeOH}(25 \% w / w, 1.85 \mathrm{~mL}, 8.1 \mathrm{mmol})$ was added. The reaction mixture was heated under reflux for $20 \mathrm{~min}$ and then allowed to cool down to room temperature. The solvent was removed in vacuo and the residue was dissolved in $\mathrm{CH}_{2} \mathrm{Cl}_{2}(500 \mathrm{~mL})$. This mixture was washed with $\mathrm{H}_{2} \mathrm{O}(3 \times 200 \mathrm{~mL})$ and dried $\left(\mathrm{MgSO}_{4}\right)$ before the solvent was removed in vacuo to produce a yellow solid containing 6 , which was used in the next reaction without further purification. The crude product containing the MPTTF compound 6, 4-brombenzaldehyd (0.681 g, $3.68 \mathrm{mmol}), \mathrm{CuI}(0.315 \mathrm{~g}$, $1.65 \mathrm{mmol})$, and $\mathrm{K}_{3} \mathrm{PO}_{4}(0.548 \mathrm{~g}, 2.58 \mathrm{mmol})$ were dissolved in anhydrous THF $(20 \mathrm{~mL})$ and degassed $\left(\mathrm{N}_{2}, 20 \mathrm{~min}\right)$ before \pm trans 1,2 diaminocyclohexane $(0.40 \mathrm{~mL}, 0.38 \mathrm{~g}, 3.3 \mathrm{mmol})$ was added. The reaction mixture was heated to $105^{\circ} \mathrm{C}$ under microwave (MW) irradiation for $3 \mathrm{~h}$ and then cooled to room temperature before the solvent was removed in vacuo. The crude product was dissolved in $\mathrm{CH}_{2} \mathrm{Cl}_{2}$ $(500 \mathrm{~mL})$ and washed with $\mathrm{H}_{2} \mathrm{O}(3 \times 250 \mathrm{~mL})$. The aqueous phases were combined and extracted with $\mathrm{CH}_{2} \mathrm{Cl}_{2}(16 \times 250 \mathrm{~mL})$. The combined organic phases were dried $\left(\mathrm{MgSO}_{4}\right)$ and Celite 545 $(20 \mathrm{~mL})$ was added, before the solvent was removed in vacuo. The resulting residue was purified by column chromatography (silica gel: 1. EtOAc, 2. $\mathrm{CH}_{2} \mathrm{Cl}_{2}$ ) and the broad yellow band was collected and concentrated to give a yellow powder, which was recrystallized from PhMe (400 mL) and washed with cold PhMe $\left(0{ }^{\circ} \mathrm{C}, 50 \mathrm{~mL}\right)$ providing the title compound 7 as an orange powder. Yield $(0.143 \mathrm{~g}$, 41\%). Characterization: M.p. > $250{ }^{\circ} \mathrm{C} .{ }^{1} \mathrm{H} \mathrm{NMR}\left(\left(\mathrm{CD}_{3}\right)_{2} \mathrm{SO}\right): \delta=7.66(\mathrm{~s}, 2 \mathrm{H}), 7.77(\mathrm{~s}, 2 \mathrm{H}), 7.98(\mathrm{~s}, 2 \mathrm{H})$, $9.97(\mathrm{~s}, 1 \mathrm{H}, \mathrm{CHO})$, the signal form the four $\mathrm{CH}_{2}$ protons are obscured under the water signal present in the NMR solvent. ${ }^{1} \mathrm{H}$ NMR $\left(\mathrm{CDCl}_{3}\right): \delta=3.31$ (bs, $\left.4 \mathrm{H}\right), 7.00$ (bs, 2H); 7.44 (bs, 2H), 7.94 (bs, $\left.2 \mathrm{H}\right), 9.98$ (s, 1H). MS (ESI): $m / z=436\left(\mathrm{M}^{+}\right)$. HiRes-FT ESI-MS: Calculated $m / z=436.9165 ;$ Found $m / z=436.9140$. IR (KBr): $v / \mathrm{cm}^{-1}=2921 ; 2844 ; 1690 ; 1600 ; 1584 ; 1519 ; 1492 ; 1391 ; 1311 ; 1172$.

Compound 9: A solution of the phosphonated PTM derivative 8 [17] (219 mg. $0.25 \mathrm{mmol})$ was dissolved in anhydrous THF $(50 \mathrm{~mL})$ under strict inert conditions and cooled down to $-78^{\circ} \mathrm{C}$. Potassium tert-butoxide $(84 \mathrm{mg}, 0.75 \mathrm{mmol}$ ) was added and the reaction mixture was stirred for $20 \mathrm{~min}$ to form the yellow-orange ylide. Subsequently, compound 7 (120 mg, $0.27 \mathrm{mmol})$ was added and the reaction mixture was allowed up to room temperature and then stirred for 3 days. Then the reaction mixture was extracted with $\mathrm{CH}_{2} \mathrm{Cl}_{2}(150 \mathrm{~mL})$ washed with $\mathrm{H}_{2} \mathrm{O}(75 \mathrm{~mL})$, and dried $\left(\mathrm{MgSO}_{4}\right)$ before the solvents were evaporated under reduced pressure. Finally, the product was purified by column chromatography (silica gel: ether/hexane 1:1) to obtain compound 9 as a light yellow powder. Yield (150 mg, 52\%). Characterization: $\left.{ }^{1} \mathrm{H} \mathrm{NMR}\left(400 \mathrm{MHz}, \mathrm{CD}_{3}\right){ }_{2} \mathrm{SO}\right): \delta=7.75(\mathrm{~d}, 2 \mathrm{H}, J=8.6 \mathrm{~Hz}), 7,58$ $(\mathrm{d}, 2 \mathrm{H}, J=8.6 \mathrm{~Hz}), 7.55(\mathrm{~s}, 2 \mathrm{H}), 7.22(\mathrm{~d}, 1 \mathrm{H}, J=16.6 \mathrm{~Hz}), 7.13(\mathrm{~d}, 1 \mathrm{H}, J=16.6 \mathrm{~Hz}) ; 6.94(\mathrm{~s}, 1 \mathrm{H}) ; 3.41(\mathrm{~s}$, 4H). FT-IR: $v / \mathrm{cm}^{-1}=2922(\mathrm{w}), 2851(\mathrm{w}), 2743(\mathrm{w}), 1603(\mathrm{~m}, \mathrm{CH}=\mathrm{CH}), 1519(\mathrm{~s}), 1486(\mathrm{w}), 1461(\mathrm{w})$, 1365 (w), 1337 (w), 1311 (s), 1298 (s), 1187 (m), 1138 (m), 1038 (m), 967 (m), 934 (m), 875 (w), 808 (s), $748(\mathrm{~m}), 719(\mathrm{w}), 685(\mathrm{w}), 669(\mathrm{~s})$. LDI-TOF (positive mode): $\mathrm{m} / \mathrm{z}\left(\mathrm{amu} / \mathrm{e}^{-}\right): 1158.944\left(\mathrm{M}^{+*}\right)$; (negative mode): $m / z\left(\mathrm{amu} / \mathrm{e}^{-}\right): 1158.845\left(\mathrm{M}^{-\cdot}\right)$. Cyclic voltammetry $\left(\mathrm{Bu}_{4} \mathrm{NPF}_{6} 0.1 \mathrm{M}\right.$ in $\mathrm{CH}_{2} \mathrm{Cl}_{2}$ as electrolyte): $E_{\frac{1}{2}}^{o x 1}=+0.425 \mathrm{~V} ; E_{\frac{1}{2}}^{o x 2}=+0.925$ V. M.p.: $220{ }^{\circ} \mathrm{C}$. 
Compound 2: Tetrabutylammonium hydroxide (1.0 M in methanol, $60 \mu \mathrm{L}, 0.060 \mathrm{mmol})$ was added to a solution of compound $9(50 \mathrm{mg}, 0.043 \mathrm{mmol})$ in distilled THF $(20 \mathrm{~mL})$ and the purple solution was stirred for $2 \mathrm{~h}$. Then $\mathrm{AgNO}_{3}(12 \mathrm{mg}, 0.071 \mathrm{mmol})$ dissolved in $\mathrm{MeCN}(10 \mathrm{~mL})$ was added and the reaction mixture was stirred for additional $60 \mathrm{~min}$. The solution changes from purple to dark brown and a precipitate of silver $\left(\mathrm{Ag}^{0}\right)$ was formed. The reaction mixture was subsequently filtered and the filtrate was evaporated under reduced pressure. Finally, the product was purified by flash column chromatography (silica gel: $\mathrm{CH}_{2} \mathrm{Cl}_{2}$ /hexane 1:1) affording the radical dyad 2 as a dark reddish-brown powder. Yield (35 mg, 69\%). Characterization: FT-IR: $v / \mathrm{cm}^{-1}=2952(\mathrm{w}), 2918(\mathrm{w}), 2853(\mathrm{w}), 1602$ $(\mathrm{m}, \mathrm{CH}=\mathrm{CH}), 1519(\mathrm{~s}), 1484(\mathrm{w}), 1461(\mathrm{w}), 1430(\mathrm{w}), 1380(\mathrm{w}), 1361(\mathrm{w}), 1333(\mathrm{~m}), 1309(\mathrm{~s}), 1298(\mathrm{~s})$, $1257(\mathrm{~m}), 1228(\mathrm{w}), 1183(\mathrm{w}), 1155(\mathrm{w}), 1118(\mathrm{w}), 1038(\mathrm{~m}), 966(\mathrm{w}), 935(\mathrm{~m}), 859(\mathrm{w}), 814(\mathrm{~s}), 766(\mathrm{w})$, $752(\mathrm{w}), 737(\mathrm{~m}), 707(\mathrm{~m}), 666(\mathrm{w}), 651$ (s). UV-VIS-NIR $\left(\mathrm{CH}_{2} \mathrm{Cl}_{2}, \lambda_{\max } / \mathrm{nm}, \varepsilon / \mathrm{M}^{-1} \cdot \mathrm{cm}^{-1}\right): 325(22269)$, 370 (22658), 386 (31503), 437 (12011). LDI-TOF (positive mode): $m / z\left(\mathrm{amu} / \mathrm{e}^{-}\right): 1158.396\left(\mathrm{M}^{+\cdot}\right)$. Cyclic voltammetry $\left(\mathrm{Bu}_{4} \mathrm{NPF}_{6} 0.1 \mathrm{M}\right.$ in $\mathrm{CH}_{2} \mathrm{Cl}_{2}$ as electrolyte): $E_{\frac{1}{2}}{ }^{1}=-0.220 \mathrm{~V} ; E_{\frac{1}{2}}{ }^{2}=+0.510 \mathrm{~V} ; E_{\frac{1}{2}}{ }^{3}=+0.953 \mathrm{~V}$. $\operatorname{ESR}\left(\mathrm{CH}_{2} \mathrm{Cl}_{2}\right): \mathrm{g}=2.0025 ; \mathrm{a}_{\mathrm{H}}=1.9 \mathrm{~Hz} ; \Delta \mathrm{H}_{\mathrm{pp}}=1.1 \mathrm{~Hz}$. M.p.: $220^{\circ} \mathrm{C}$.

\section{Conclusions}

In summary, we have reported the synthesis and characterization of the new dyad 2 based on the EDT-MPTTF moiety as electron donor linked to a PTM radical as electron acceptor through a phenyl-vinyelene bridge. This new dyad exhibits optimal electronic properties in solution and have the potential to give rise to new radical conductors in the solid state. Neutral and charge transfer salt crystals based on this system could have a potential use in spintronics if they are able to combine both conductivity and magnetism in a cooperative way.

Supplementary Materials: The following are available online at www.mdpi.com/2312-7481/2/4/46/s1, Figure S1: ${ }^{1} \mathrm{H}$ NMR spectrum of 9, Figure S2: IR spectrum of $\mathbf{2}$ and 9, Figure S3: CVs of $\mathbf{2}$ and 9, Figure S4: UV-vis-NIR of 2+ in THF. Figure S5: Frontier molecular orbital energy diagrams (left) and topologies (right) for the dyads $\mathbf{1}$ (black) and $\mathbf{2}$ (red). The two series of lines represent the orbitals associated to the spin up $(\alpha)$ and spin down ( $\beta$ ), respectively.

Acknowledgments: This work was supported by the EU ITN iSwitch 642196 and "Nano2Fun" 607721 DGI grant (BeWell; CTQ2013-40480-R), the Networking Research Center on Bioengineering, Biomaterials, and Nanomedicine (CIBER-BBN), and the Generalitat de Catalunya (grant 2014-SGR-17). ICMAB acknowledges support from the Spanish Ministry of Economy and Competitiveness, through the "Severo Ochoa" Programme for Centres of Excellence in R\&D (SEV-2015-0496). In Denmark, this work was supported by the Danish Council for Independent Research I Natural Sciences (\#11-106744). M.S. is grateful to Spanish Ministerio de Educación, Cultura y Deporte for a FPU grant. We thank Vega Lloveras for ESR spectroscopy and Amable Bernabé for MALDI spectroscopy.

Author Contributions: M.S., D.B. and M.J. synthesized and characterized the compounds; V.D.-C. and J.C. performed the theoretical calculations; J.O.J., I.R., C.R and J.V. conceived and designed the experiments.

Conflicts of Interest: The authors declare no conflict of interest.

\section{References}

1. Haddon, R.C. Design of organic metals and superconductors. Nature 1975, 256, 394-396. [CrossRef]

2. Cordes, A.W.; Haddon, R.C.; Oakley, R.T. Molecular conductors from neutral heterocyclic $\pi$-radicals. Adv. Mater. 1994, 6, 798-802. [CrossRef]

3. Kobayashi, A.; Fujiwara, E.; Kobayashi, H. Single-Component Molecular Metals with Extended-TTF Dithiolate Ligands. Chem. Rev. 2004, 104, 5243-5264. [PubMed]

4. Pal, S.K.; Itkis, M.E.; Tham, F.S.; Reed, R.W.; Oakley, R.T.; Haddon, R.C. Resonating valence-bond ground state in a phenalenyl-based neutral radical conductor. Science 2005, 309, 281-284. [CrossRef] [PubMed]

5. Mandal, S.K.; Samanta, S.; Itkis, M.E.; Jensen, D.W.; Reed, R.W.; Oakley, R.T.; Tham, F.S.; Donnadieu, B.; Haddon, R.C. Resonating valence bond ground state in oxygen-functionalized phenalenyl-based neutral radical molecular conductors. J. Am. Chem. Soc. 2006, 128, 1982-1994. [CrossRef] [PubMed]

6. Pal, S.K.; Itkis, M.E.; Tham, F.S.; Reed, R.W.; Oakley, R.T.; Haddon, R.C. Trisphenalenyl-based neutral radical molecular conductor. J. Am. Chem. Soc. 2008, 130, 3942-3951. [CrossRef] [PubMed] 
7. Tenn, N.; Bellec, N.; Jeannin, O.; Piekara-sady, L.; Auban-senzier, P. A Single-Component Molecular Metal Based on a Thiazole Dithiolate Gold Complex. J. Am. Chem. Soc. 2009, 131, 16961-16967. [CrossRef] [PubMed]

8. Yu, X.; Mailman, A.; Lekin, K.; Assoud, A.; Robertson, C.M.; Noll, B.C.; Campana, C.F.; Howard, J.A.K.; Dube, P.A.; Oakley, R.T. Semiquinone-bridged bisdithiazolyl radicals as neutral radical conductors. J. Am. Chem. Soc. 2012, 134, 2264-2275. [CrossRef] [PubMed]

9. Leitch, A.A.; Lekin, K.; Winter, S.M.; Downie, L.E.; Tsuruda, H.; Tse, J.S.; Mito, M.; Desgreniers, S.; Dube, P.A.; Zhang, S.; et al. From magnets to metals: The response of tetragonal bisdiselenazolyl radicals to pressure. J. Am. Chem. Soc. 2011, 133, 6050-6060. [CrossRef] [PubMed]

10. Isono, T.; Kamo, H.; Ueda, A.; Takahashi, K.; Nakao, A.; Kumai, R.; Nakao, H.; Kobayashi, K.; Murakami, Y.; Mori, H. Hydrogen bond-promoted metallic state in a purely organic single-component conductor under pressure. Nat. Commun. 2013, 4, 1344-1346. [CrossRef] [PubMed]

11. Ueda, A.; Yamada, S.; Isono, T.; Kamo, H.; Nakao, A.; Kumai, R.; Nakao, H.; Murakami, Y.; Yamamoto, K.; Nishio, Y.; et al. Hydrogen-Bond-Dynamics-Based Switching of Conductivity and Magnetism: A Phase Transition Caused by Deuterium and Electron Transfer in a Hydrogen-Bonded Purely Organic Conductor Crystal. J. Am. Chem. Soc. 2014, 136, 12184-12192. [CrossRef] [PubMed]

12. Souto, M.; Solano, M.V.; Jensen, M.; Bendixen, D.; Delchiaro, F.; Girlando, A.; Painelli, A.; Jeppesen, J.O.; Rovira, C.; Ratera, I.; et al. Self-Assembled Architectures with Segregated Donor and Acceptor Units of a Dyad Based on a Monopyrrolo-Annulated TTF-PTM Radical. Chem. Eur. J. 2015, 21, 8816-8825. [CrossRef] [PubMed]

13. Souto, M.; Cui, H.; Peña-Álvarez, M.; Baonza, V.G.; Jeschke, H.O.; Tomic, M.; Valent, R.; Blasi, D.; Ratera, I.; Rovira, C.; et al. Pressure-Induced Conductivity in a Neutral Nonplanar Spin-Localized Radical. J. Am. Chem. Soc. 2016, 138, 11517-11525. [CrossRef] [PubMed]

14. Souto, M.; Rovira, C.; Ratera, I.; Veciana, J. TTF-PTM dyads: From switched molecular self assembly in solution to radical conductors in solid state. CrystEngComm 2016. [CrossRef]

15. Pop, F.; Avarvari, N. Covalent non-fused tetrathiafulvalene-acceptor systems. Chem. Commun. 2016, 52, 7906-7927. [CrossRef] [PubMed]

16. Rovira, C. Bis(ethylenethio)tetrathiafulvalene (BET-TTF) and related dissymmetrical electron donors: From the molecule to functional molecular materials and devices (OFETs). Chem. Rev. 2004, 104, 5289-5317. [CrossRef] [PubMed]

17. Rovira, C.; Ruiz-Molina, D.; Elsner, O.; Vidal-Gancedo, J.; Bonvoisin, J.; Launay, J.P.; Veciana, J. Influence of topology on the long-range electron-transfer phenomenon. Chem. Eur. J. 2001, 7, 240-250. [CrossRef]

18. Simonsen, K.B.; Svenstrup, N.; Lau, J.; Simonsen, O.; Mørk, P.; Kristensen, G.J.; Becher, J. Sequential Functionalisation of Bis-Protected Tetrathiafulvalene-dithiolates. Synthesis (Stuttg.) 1996, 1996, 407-418. [CrossRef]

19. O'Driscoll, L.J.; Andersen, S.S.; Solano, M.V.; Bendixen, D.; Jensen, M.; Duedal, T.; Lycoops, J.; Van Der Pol, C.; Sørensen, R.E.; Larsen, K.R.; et al. Advances in the synthesis of functionalised pyrrolotetrathiafulvalenes. Beilstein J. Org. Chem. 2015, 11, 1112-1122. [CrossRef] [PubMed]

20. Guasch, J.; Grisanti, L.; Lloveras, V.; Vidal-Gancedo, J.; Souto, M.; Morales, D.C.; Vilaseca, M.; Sissa, C.; Painelli, A.; Ratera, I.; et al. Induced self-assembly of a tetrathiafulvalene-based open-shell dyad through intramolecular electron transfer. Angew. Chem. Int. Ed. 2012, 51, 11024-11028. [CrossRef] [PubMed]

21. Souto, M.; Guasch, J.; Lloveras, V.; Mayorga, P.; López Navarrete, J.T.; Casado, J.; Ratera, I.; Rovira, C.; Painelli, A.; Veciana, J. Thermomagnetic molecular system based on TTF-PTM radical: Switching the spin and charge delocalization. J. Phys. Chem. Lett. 2013, 4, 2721-2726. [CrossRef]

22. Guasch, J.; Grisanti, L.; Souto, M.; Lloveras, V.; Vidal-Gancedo, J.; Ratera, I.; Painelli, A.; Rovira, C.; Veciana, J. Intra- and intermolecular charge transfer in aggregates of tetrathiafulvalene-triphenylmethyl radical derivatives in solution. J. Am. Chem. Soc. 2013, 135, 6958-6967. [CrossRef] [PubMed]

23. Sugawara, T.; Komatsu, H.; Suzuki, K. Interplay between magnetism and conductivity derived from spin-polarized donor radicals. Chem. Soc. Rev. 2011, 40, 3105-3118. [CrossRef] [PubMed]

(C) 2016 by the authors; licensee MDPI, Basel, Switzerland. This article is an open access article distributed under the terms and conditions of the Creative Commons Attribution (CC-BY) license (http:/ / creativecommons.org/licenses/by/4.0/). 